\title{
EL DERECHO A LA VIDA Y A LA SALUD DE LOS NEONATOS ABANDONADOS EN ECUADOR
}

THE Right TO LIFE AND HEALTH OF ABANDONED NEONATES IN ECUADOR

\author{
Jorge Luis Cueva Flores* \\ Carmen Avelina Eguiguren Eguiguren ${ }^{* *}$
}

Resumen: El abandono de recién nacidos es una problemática a nivel mundial que debería provocar reflexión social y jurídica, a fin de obtener la protección del neonato. Ecuador no es una excepción y anualmente se reportan abandonos de neonatos en condiciones alarmantes. La metodología usada consiste en un análisis sobre la vulnerabilidad de neonatos abandonados basado en casos reales, donde se observa la experiencia de los buzones estatales para su acogida. Tal problemática se analiza en el siguiente orden: Después de una breve la introducción, se aborda teóricamente el derecho a la vida y al cuidado frente al abandono de neonatos. En el siguiente capítulo se trata de las obligaciones legales e institucionales estatales con respecto al niño. A continuación se tratan sobre el acogimiento institucional estatal, sobre la viabilidad jurídica de establecer buzones para entregar bebés en Ecuador en condiciones seguras, y terminamos con una conclusiones sintéticas. El estudio exploratorio busca definir cuán viable es replicar en el Ecuador el proyecto de buzones estatales para entregar bebés en condiciones seguras, a fin de proteger la vida e integridad del niño, en cuanto son

\footnotetext{
* Abogado y Magíster en Derecho Civil y Procesal por la Universidad Técnica Particular de Loja (Ecuador) y docente del Departamento de Ciencias Jurídicas de la misma institución. jlcuevaxxx@utpl.edu.ec

** Doctora en Derecho y Ciencias Sociales por la Universidad Nacional de Educación a Distancia UNED (España). Docente titular del Departamento de Ciencias Jurídicas de la Universidad Técnica Particular de Loja (Ecuador). Procuradora Universitaria de la Universidad Técnica Particular de Loja. ceguiguren@utpl.edu.ec
} 
constitucionalmente protegidos. Para ello, resulta necesario la despenalización del abandono de neonatos en condiciones seguras.

Palabras clave: Abandono, acogimiento, babyklappe, neonato, vida

Abstract: The abandonment of newborns is a worldwide problem that should stir social and legal reflection, in order to obtain protection of the newborn. Ecuador is not an exception and every year multiple newborn abandonments are reported in alarming conditions. About methodology, we use here an analysis based on realistic cases to show the vulnerability of abandoned infants and the experience of State sponsored baby hatches for their reception. This problem is analyzed with the following order: after an introduction, we see the right to life and care regarding newborns' abandonment. Next Chapter is about the legal and institutional obligations of the State with respect to the child. Then we see the State foster care, the legal viability in Ecuador to establish baby hatches in order to deliver babies in safe conditions, and, at last, the conclusions. This exploratory study seeks the viability of replicating the State baby hatches project to deliver babies in safe conditions, in Ecuador, in order to protect life and integrity of the child, that is constitutionally protected. For this purpose, decriminalization of infants' abandonment in safe conditions is needed.

Keywords: Abandonment, Foster Care, Babyklappes, Newborn, Life

Sumario. I. Introducción. II. Derecho a la vida y al cuidado frente al abandono de neonatos. II.1. El Derecho a la vida y a su cuidado en la normativa ecuatoriana. II.2 La sociedad ecuatoriana y el abandono de niños recién nacidos. III. Obligaciones legales e institucionales del estado con respecto al niño. IV. Acogimiento institucional estatal. IV.1. Deberes del Estado. IV.2. Buzones para entregar bebés en condiciones seguras o "Babyklappe". V. Viabilidad jurídica y estatal para establecer buzones para entregar bebés en Ecuador en condiciones seguras. VI. Conclusiones. Referencias.

\section{INTRODUCCIÓN}

El abandono de niños recién nacidos se debate en las sociedades habitualmente - desde el punto de vista social, jurídico y de las políticas públicas. Ecuador no es ajeno — ni lo ha sido — a este debate social. El país registra abandono de niños recién nacidos en condiciones anónimas y, a menudo, sumamente precarias. Basureros, baños y lotes baldíos son 
escenarios frecuentes de este tipo de abandono, lo que se constituye en una lacra social que atenta contra los derechos fundamentales del niño.

Las siguientes estadísticas proporcionadas por la Dirección Nacional de Policía Especializada para Niños, Niñas y Adolescentes de la Policía Nacional del Ecuador (Departamento de Gestión Operativa y DAI de la DINAPEN $)^{1}$ registran el número de niños y niñas recién nacidos que han sido abandonados, entre los años 2016-2018: en 2016 hubo 17 recién nacidos abandonados ( 11 hombres y 6 mujeres); en 2017 hubo 8 (5 mujeres y 3 hombres); y en 2018 hubo 12 (9 hombres y 3 mujeres). El informe incluye un gráfico evolutivo, por años y por meses:

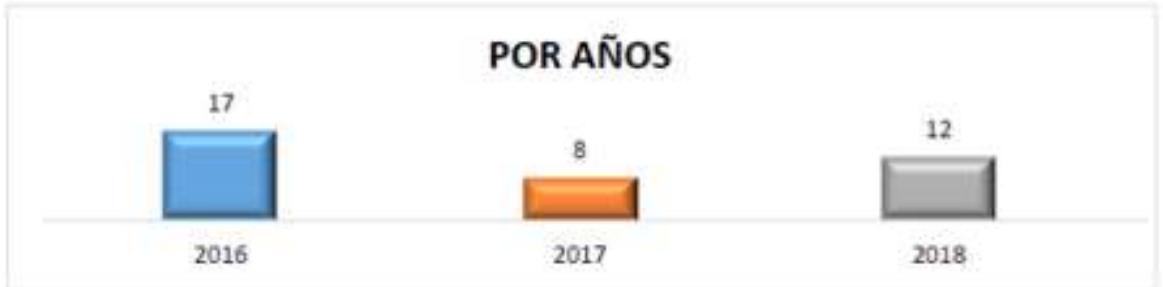

Gráfico 1. Fuente: Dirección Nacional de Policía Especializada para niños, niñas y adolescentes de la Policía Nacional del Ecuador (Dpto. Gestión Operativa y DAI), I-2019.

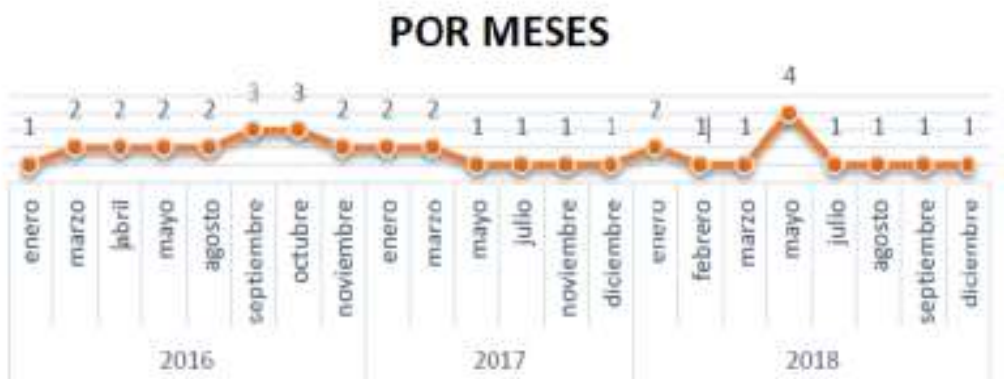

Gráfico 2. Fuente: Dirección Nacional de Policía Especializada para niños, niñas y adolescentes de la Policía Nacional del Ecuador (Dpto. Gestión Operativa y DAI), I-2019.

Además, el informe detalla los sitios en los que, habitualmente, se abandona a los recién nacidos. Las mayores incidencias de abandonos ocurren en la vía pública y en terrenos baldíos; le siguen las casas de salud $\mathrm{y}$, en menor cantidad, en el bosque, domicilios particulares, iglesia, montaña, tacho de basura e interior de un bus interprovincial:

\footnotetext{
${ }^{1}$ La DINAPEN proporcionó las estadísticas a los investigadores en enero de 2019, con la advertencia de que se trata de un documento reservado y que el usuario que haga mal uso del mismo, será el responsable por ello.
} 


\section{LUGAR DONDE FUE ABANDONADO}

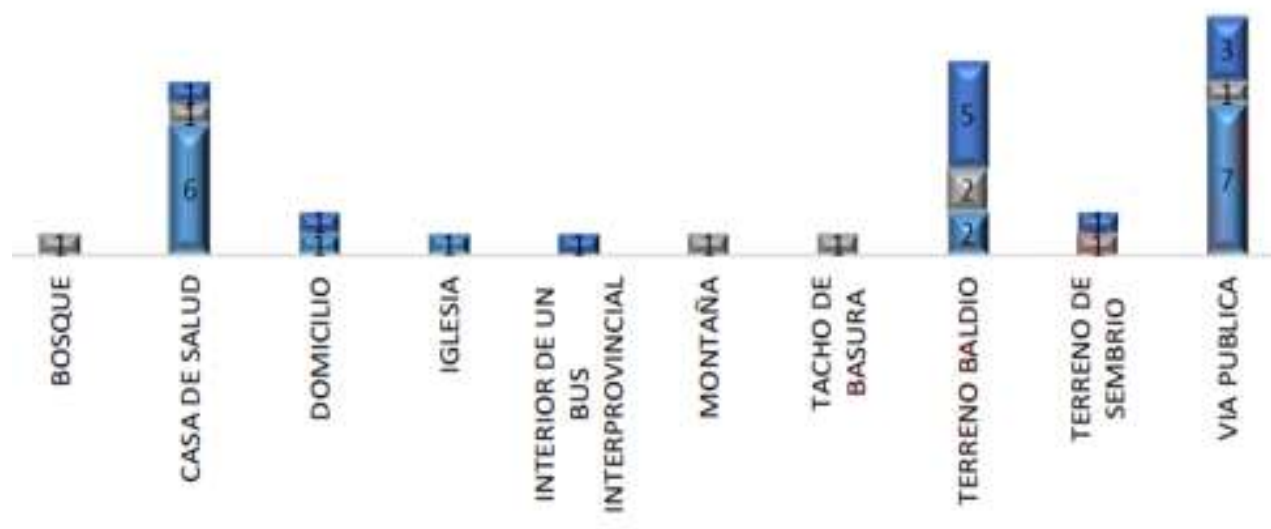

A2016 2017 a 2018

Gráfico 3. Fuente: Dirección Nacional de Policía Especializada para niños, niñas y adolescentes de la Policía Nacional del Ecuador (Dpto. Gestión Operativa y DAI), I-2019.

Del informe se colige que el número de recién nacidos abandonados entre los años 2016 a 2018 suman 37. Aunque no se registran (al menos, oficialmente) un gran número de neonatos abandonados en los tres años objeto de este estudio, la cifra mencionada igual debe provocar acciones estatales para el cuidado emergente del niño o niña, y posterior ubicación en un centro de acogimiento estatal para inicio del proceso de adopción. Por tratarse de un recién nacido abandonado, no procede el acogimiento familiar por desconocimiento del vínculo de consanguinidad; lo procedente, por tanto, es el acogimiento institucional por parte del Estado.

Si bien el tema del aborto puede estar ligado a circunstancias distintas a las del abandono luego del parto, mantiene alguna relación con esta investigación, donde se analiza la propuesta de unos buzones estatales para entregar al neonato en condiciones seguras: estos buzones podrían ser una alternativa válida para la mujer que se encuentra en la disyuntiva entre abortar o no, para finalmente decidir culminar el proceso de gestación. No es intención de este trabajo acometer el tema del aborto ni su problemática, pues ciertamente es un tópico amplio que amerita investigación aparte; sin embargo, la cuestión de la entrega de niños recién nacidos en condiciones seguras, pudiera eventualmente causar desistimiento de aborto en una mujer que ha decidido no asumir la responsabilidad de la crianza del niño.

El Código Civil Francés (2015) incorpora la figura del "parto anónimo", donde se determina que la mujer embarazada puede solicitar, en el momento del parto, que su identidad se mantenga en secreto, y que el 
recién nacido pase al proceso de acogimiento institucional para, posteriormente, sujetarse a los procesos de adopción (cfr. arts. 57 y 326). La misma ley permite a la madre que guarde su identidad y la posibilidad de emitir su opinión sobre los nombres que se desea asignar al recién nacido.

Al tenor de la norma antes citada, Ordás (2015, pp. 97-144) realiza un análisis con respecto a si existe legalidad en el denominado parto anónimo. Es claro que el parto anónimo conlleva ocultar estrictamente la identidad de la mujer al momento del parto, lo cual contradice el derecho a la identidad que tiene el recién nacido, derecho relacionado a conocer la información sobre sus padres biológicos; pero esta línea de reflexión también debe conducir al punto de vista de protección de la vida, pues una mujer que decida acogerse al secreto de identidad en el parto, también protege la vida, integridad y salud del que está por nacer.

Es probable que la posibilidad de un parto anónimo brinde a aquellas mujeres que, por cualquier circunstancia hayan decidido no hacerse cargo de su hijo, la posibilidad de gestar y parir en condiciones seguras. Incluso ello puede influir con respecto a decisiones como el aborto, el infanticidio o el abandono del neonato en condiciones inaceptables, como aquellos abandonos mencionados en las estadísticas antes mostradas.

No escapará al razonamiento del lector el problema que representa el abandono del niño en buzones estatales o el parto anónimo, frente al derecho del menor a conocer sus orígenes y todo lo que de ello se desprende. Es probable que esta objeción se resuelva, al menos en parte, con la información sobre datos y condiciones de nacimiento, tales como lugar de nacimiento; fecha, día y hora; y, datos sobre proceso de acogimiento institucional, para que sean de acceso al titular de los derechos, en su momento.

Es de esperar que la entrega de recién nacidos en buzones estatales y en condiciones seguras, así como el parto anónimo, precautelen la salud y la vida del menor, para que sea atendido de forma inmediata por profesionales de la salud, aun cuando ello conlleve el desconocimiento de los nombres de su madre. Con todo, el derecho de la vida es jerárquicamente superior al de la identidad (Constitución, art. 66.1). Este artículo pretende llamar la atención sobre la necesidad de que el Estado dé protección a la vida del que está por nacer y del recién nacido.

Según parte de la doctrina ${ }^{2}$, la experiencia de los buzones estatales para dejar al niño recién nacido en condiciones seguras y salvaguardando el anonimato, es una experiencia exitosa replicable y recomendable en países

${ }^{2}$ V.gr. Bermeo (2016), Dittrich (2018) y Palacios (2015), quienes consideraron que los buzones estatales para dejar neonatos en condiciones seguras han demostrado ser factibles y exitosos. 
en los que se busca preservar los intereses superiores de grupos vulnerables, como la niñez. Ecuador demuestra esa intención, no sólo en la letra de su Carta Magna y en otras normas, sino también en la estructura institucional para acogimiento y adopción seguros.

Aquí exploraremos en el marco conceptual y jurídico de la posibilidad de que el Estado ecuatoriano asuma el proyecto de los buzones estatales para entrega de niños recién nacidos en condiciones seguras. Las fuentes son oficiales, normativas, teóricas y comunicacionales.

\section{DERECHO A LA VIDA Y AL CUIDADO FRENTE AL ABANDONO DE NEONATOS}

La vida de una persona ha sido respetada y protegida como bien jurídico desde tiempos remotos. Esto es un derecho intrínseco defendido por el Estado ecuatoriano. Por lo tanto, goza de un respaldo frente a las amenazas comunes que afrontan los humanos, y en especial de los considerados "vulnerables", entre los que se encuentran quienes están por nacer y los recién nacidos.

«La familia es un fenómeno natural, tan antiguo como la humanidad misma, con la que es consubstancial» (Lacruz, 2011, p. 7). Es dentro de la familia donde se desarrolla de forma natural el niño en sus primeros años. El derecho a la vida y a la protección del recién nacido, por tanto, deben ser salvaguardados en primer lugar por la familia. La Constitución de la República del Ecuador (art. 67) reconoce la familia en sus diversos tipos y proclama que el Estado la protegerá como núcleo fundamental de la sociedad, garantizando condiciones que favorezcan integralmente la consecución de sus fines. Barahona analiza el texto constitucional de la siguiente forma:

«En este contexto, podemos encontrar en los tratados internacionales, constituciones, leyes y demás disposiciones jurídicas de los diferentes Estados definiciones que tuvieron que ser reformadas o reinterpretadas para adaptarse a la dinámica y exigencia social. Por esto autores como Germán Martínez afirman que "la familia es un concepto jurídico indeterminado, el cual es afectado en su configuración por una realidad cambiante propia de un proceso histórico, al cual está supeditado la vida en sociedad", dejando en claro que no se puede hablar de una definición y forma única de familia, pues la construcción social va determinando lo dúctil de la institución y las nuevas formas que adopta» (Barahona, 2015, p. 72).

El derecho a la vida y a la protección de ésta por parte del Estado se relaciona directamente con la persona y su concepto. Para Larrea Holguín (2008, p. 149) el concepto de persona pertenece ante todo a la filosofía, y ha 
sido desarrollado especialmente por la filosofía cristiana; sin embargo, conceptualiza a la persona en el plano jurídico como el ser capaz de tener derechos y obligaciones, el sujeto de derecho.

En cuanto a la existencia de la persona humana, el mismo autor establece que «al menos para los efectos jurídicos, supone la vida» (Larrea Holguín, 2008, v. I, p. 175). Si todavía no ha llegado a la vida, dice, no es más que una posibilidad. Existe vida, para este autor, desde que el principio vital anima a un cuerpo, es decir desde el momento en que se unen alma y cuerpo para formar esta sustancia compuesta que es el hombre, lo que sucede en el momento de la fecundación.

Para efectos del Código Civil ecuatoriano (cfr. art. 60), el nacimiento de una persona fija el principio de su existencia legal, desde que es separada completamente de su madre. En tal virtud y desde el punto de vista jurídico, el niño que ha sido separado completamente de su madre es sujeto de todos los derechos, sin perjuicio de los que le asisten desde su concepción. En especial, el de la vida y su protección.

El informe del Consejo Nacional para la Igualdad Intergeneracional (2014, p. 25) establece que, en países como Ecuador, de renta media alta, los derechos de primera generación están ampliamente cubiertos, pero que uno de los mayores desafíos es cerrar la brecha de la protección social y, en el caso de la infancia, la brecha de protección especial. Es decir, la falta de recursos económicos podría ser un factor importante que limita la inversión en sistemas de protección para las personas en estado de vulnerabilidad.

Es este mismo informe que da cuenta que en Ecuador, para el año 2014, la población de niños, niñas y adolescentes se acercaba a los 6 millones de habitantes (ibid., p. 45). Dentro de este grupo, los niños y adolescentes entre 10 y 17 años representa el 55\% de ese valor. La pobreza, explica el documento, siempre es mayor en el caso de la niñez y la adolescencia, porque precisamente los hogares pobres son los que mayor número de niños y niñas tienen.

Otro dato citado por el informe es que en Ecuador la cobertura de parto institucional, sea en instancias públicas o privadas, llega al 94\%. Esta cifra, sin embargo, debe entenderse desde los nacimientos registrados, pues el mismo documento (2014, pp. 83-85) señala que, si bien los niños deben ser protegidos por su familia, hay un grupo de infantes que llegan al mundo sin ser esperados y que no son registrados al nacer, impidiendo con ello la verificación real de la edad de los niños, lo que oculta el cumplimiento de la edad mínima legal y que se constituye en un factor que favorece al tráfico y la explotación de niños. Son datos que pueden relacionarse con el abandono de niños recién nacidos. 
Quizá una cifra que también esté relacionada con expósitos es la que apunta el informe ya citado en cuanto a partos en adolescentes. Para el año 2009 se registraron 2083 partos en niñas de 10 a 14 años (2014, pp. 97-98); y el trecho de edad en el que se registraron el mayor porcentaje de partos en adolescentes es el de 15 a 19 años (60.000 partos de madres adolescentes).

La estigmatización que sufren las adolescentes embarazadas se refleja en una encuesta que el documento cita y que refiere entrevistas a jóvenes de 15 a 17 años, en cuanto a su ámbito educativo: el 26\% de ellas sufrió burlas y juicios de parte de sus profesores. El 17\% sufrió estos ataques por parte de sus compañeros; y, una parte de ellas declaró que padeció maltrato físico y sicológico de sus parejas.

Todo ello pudiera apuntar al hecho de que algunos neonatos son abandonados a su suerte por las circunstancias socio-económicas de sus madres. No se puede descartar el hecho de que una madre que se encuentra en condiciones económicas y/o sociales precarias, abandone a su hijo por la situación misma que atraviesa.

Guillermo Cabanellas define abandono como «el desamparo de una persona a quien se debía cuidar; renuncia de un derecho o incumplimiento de un deber»; y, al abandono de personas como «el desamparo de aquellas a quienes, por algún concepto, se está obligado a proteger» (Cabanellas, 1979)

El abandono del recién nacido ha sido hecho de todos los tiempos. Así lo señala Manuel Fernández Álvarez cuando explica que, al tener acceso al Archivo Municipal de Salamanca, pudo conocer un manuscrito de fines del siglo XVI con la relación de los niños que iban apareciendo abandonados en la puerta de la Catedral. El autor resalta que, de la lectura del manuscrito, se aprecia el afán de sigilo de las familias interesadas de conseguir secreto con respeto a los expósitos, pues «importa más la honra de la familia de la madre que la vida del niño» (Fernández Álvarez, 2002, s/p: libro electrónico).

«El abandono infantil es una forma de maltrato y resulta de ciertas condiciones de tipo familiar y económicas» (Sanín, 2013, p. 99). La autora señala que la procreación de hijos naturales, que se originan fuera de matrimonio, representan riesgo de abandono de recién nacidos productos de esa procreación.

Entonces, diversos motivos como falta de recursos económicos, falta de armonía en la pareja, amenazas físicas y psicológicas, procreación que resulta de uniones incestuosas o ilegítimas, etc., pueden incidir en la decisión de abandonar un recién nacido, dejando en indefensión a esta persona vulnerable. Decisiones que son tomadas aún bajo conocimiento o desconocimiento de la existencia de normativa penal que sanciona estos actos atentatorios a la vida, tal como se determina en la normativa penal: 
«Abandono de persona.- La persona que abandone a personas adultas mayores, niñas, niños y adolescentes, mujeres embarazadas, personas con discapacidad o a quienes adolezcan de enfermedades catastróficas, de alta complejidad, raras o huérfanas, colocándolas en situación de desamparo y ponga en peligro real su vida o integridad física, será sancionada con pena privativa de libertad de uno a tres años (...)» (Código Orgánico Integral Penal, art. 153).

El abandono de personas debe ser «estrictamente sancionado» en el entorno de la sociedad «debido a que la vida de la persona abandonada se enfrenta a inminente peligro, y no solamente con el abandono, sino también con el desamparo y falta de prestación de auxilios ante los cuales se debe actuar solidariamente» (Villada, 2004, p. 236). Este autor resalta que la persona que produce el abandono, dejando a su suerte al abandonado, convierte a este último en una potencial víctima al no prestarle el cuidado necesario. Es un delito por omisión, por desatender el deber objetivo de cuidado. Defiende el derecho a la vida como el primer mandato constitucional de un Estado que se precie de ser Estado de Derecho: «No hay país que seriamente se arrogue la irrestricta defensa de los derechos humanos, sino protege severamente la vida, su dignidad, su menoscabo o rechaza cualquier modalidad de conducta que siquiera la ponga en peligro» (Villada, 2004, p. 236).

Para Manuel Ossorio (1974, p. 7), el abandono de personas es un delito que consiste «en la realización de actos intencionalmente dirigidos a poner en peligro la seguridad física de una persona que no se encuentra en condiciones de cuidarse a sí misma». De ahí que el sujeto pasivo del abandono tenga que ser un menor de determinada edad (diez años en la legislación dominante) o un incapacitado por enfermedad corporal o mental. Para Ossorio, se estima agravante la circunstancia de que, de tal abandono, cuando resulte grave daño en el cuerpo o en la salud del menor o incapaz, o la muerte, así como también que el delito sea cometido por los padres contra sus hijos y por éstos contra aquéllos, o por el cónyuge. Contrariamente, señala el autor, se estima atenuante la circunstancia de que el abandonado sea menor de tres días aún no inscrito en el Registro Civil, o si el hecho ha sido realizado para salvar el honor propio de la esposa, madre, hija o hermana.

Fernando Robles (2017, p. 41), define al abandono de personas como:

«(...) el grupo de delitos con que se protege la vida y la salud, pero que a pesar de que los bienes jurídicos son de importancia fundamental para la vida en sociedad, por la característica de su tipificación se considera que se encuentran dentro de la gama de delitos cuya gravedad es menor y sus penas son bastante bajas».

La tipificación del delito admite dos modalidades, señala Robles: la primera, que se refiere a la exposición y al peligro; $y$, la segunda, que implica 
el abandono mismo. Con respecto a abandono, explica, se ha de entender como el simple alejamiento del ámbito de protección que requiere al menos para su cuidado. Así, el alejamiento en un lugar público, por ejemplo, por una hora, ya configura el delito de abandono, siempre y cuando la causa sea injustificada e implique deberes de cuidado y asistencia.

Edgardo Donna, en línea con Gössel, ratifica que el bien jurídico amenazado cuando se practica un abandono es la vida e integral corporal de la persona abandonada. El autor afirma «que es necesario que exista un peligro real para la víctima del delito»(Donna, 1999, p. 263). Además mantiene que el tipo penal comprende dos acciones distintas, a saber: la exposición a situación de desamparo y el abandono. En cuanto a la exposición, refiere que es el acto de dejar a la víctima en lugar en el que se encuentre sin protección y en peligro a su vida y a su salud. La exposición ocurre cuando se cumplen dos presupuestos: (i) Que se sustraiga a la víctima la ayuda ajena; y, (ii) que ésta entre, a consecuencia de ello, en situación de desamparo. «Es decir, luego de la acción del autor, al sujeto pasivo le deberá resultar imposible aventar, por sí mismo, un peligro para su vida o su salud» (Donna, 1999, pp. 265-267).

En este sentido, Donna define el abandono como «colocar a la víctima en un peligro concreto, exponiendo a quien no estaba en riesgo a una situación de peligro». Y a continuación añade: «es situar a la víctima fuera del ambiente de protección, privándola de la asistencia necesaria, con la consiguiente creación de riesgo para su vida y su salud».

De las anteriores reflexiones sobre el abandono y las circunstancias que deben configurase para se adecúe al tipo penal, parecería que no incurre en el tipo penal la exposición de un menor a desamparo cuando el autor abandona a su víctima en un lugar donde es seguro que prontamente ella sea atendida, sin peligro alguno para su vida o su salud. Básicamente la razón por la que se enfatiza el hecho de la circunstancia eximente - $\mathrm{O}$ al menos atenuante - en el tipo penal de exposición a desamparo, es porque si el neonato es entregado en un buzón de asistencia estatal, su vida o salud serán prontamente protegidas, retirando del tipo penal el componente de exposición, al menos.

\section{II.1. El Derecho a la vida y a su cuidado en la normativa ecuatoriana}

En el art. 1 de la Constitución encontramos que Ecuador es un «Estado constitucional de derechos y justicia», lo que nos demanda una reflexión sobre su significado. Villar Borda (2007, p. 75) nos dice que el "Estado de derecho" se ha visto limitado a la legalidad de la administración como una primacía de la ley formal, empobreciéndose y estrechándose al quedar 
reducido a un "Estado de leyes", a través de un concepto puramente formal. Al declararse al Ecuador como un "Estado constitucional de derechos" se va más allá de lo puramente formal y se garantizan los derechos de las personas que la misma Carta declara, mediante la creación de una instancia autónoma y especializada de control constitucional.

El Estado ecuatoriano tiene incorporado el derecho a la vida y a su protección, en el ordenamiento jurídico interno, y por la jerarquía normativa de la constitución, se determina que los niños, niñas y adolescentes gozan de los derechos comunes al ser humano, conforme a su edad; y, se reconoce la vida, incluyendo el cuidado y protección desde la concepción (cfr. art. 45). $\mathrm{Y}$ es que el Estado tiene respecto de los niños bajo su jurisdicción, las obligaciones de respetar y garantizar el pleno goce y ejercicio de sus derechos, impuestos no solo en relación con el poder del Estado, sino también frente a actuaciones de terceros particulares, derivándose deberes especiales que se determinarían en función de las particulares necesidades de protección del sujeto de derecho (cfr. Nogueira, 2017, p. 416).

Para Petit (1984, p. 100) la potestad paternal pertenece al jefe de familia sobre los descendientes que forman parte de la familia civil. Se remonta a esta figura en la historia y de ella explica que no es como la autoridad del señor, una institución del derecho de gentes; es, dice, de derecho civil y no puede ejercerse más que por un ciudadano sobre un hijo también ciudadano.

Larrea Holguín (2008, v. II, pp. 278 y ss.) propone que, si bien tradicionalmente se identificaba al padre como autoridad del hogar, hoy se reconoce a un mayor ámbito de influencia a la madre, en todo lo tocante a la autoridad, explicando que son ambos progenitores la que la ejercen. Y es que el tema de la potestad de los progenitores con respecto a sus descendientes tiene relación directa con el deber objetivo de cuidado que se observará, en este caso, hacia los hijos recién nacidos. No escapará al lector que tanto la madre como el padre tienen obligación de velar por la integridad de sus hijos recién nacidos, ni que la protección de su vida y salud es inherente a esta potestad.

Además, Ecuador tiene vigente una norma especial que busca la protección de los niños, niñas y adolescentes, en la cual se ratifica nuevamente el derecho a la vida y establece su definición, agregando la prohibición de experimentar en seres humanos desde la fecundación hasta el nacimiento, cuando ponga a la persona en una situación de peligro:

«Derecho a la vida.- Los niños, niñas y adolescentes tienen derecho a la vida desde su concepción. Es obligación del Estado, la sociedad y la familia asegurar por todos los medios a su alcance, su supervivencia y desarrollo. Se prohíben los 
experimentos y manipulaciones médicas y genéticas desde la fecundación del óvulo hasta el nacimiento de niños, niñas y adolescentes; y la utilización de cualquier técnica o práctica que ponga en peligro su vida o afecte su integridad o desarrollo integral» (Código de la Niñez y Adolescencia, art. 20).

Se destaca el compromiso de un Estado garantista del derecho a la vida, que a la vez prohíbe de pena de muerte. Esto ha impulsado al Ecuador a ratificar acuerdos internacionales que buscan facilitar las relaciones entre naciones, en busca de fines comunes, como el que trata nuestro análisis, la protección de la vida; $y$, facilitar el resarcimiento de daños frente a la vulneración de derechos producidos al interno de un país.

El Estado ecuatoriano ha ratificado diversos acuerdos internacionales en defensa de la vida, como la Convención sobre los derechos del Niño (1989) que puntualiza: «Art. 6.1. Los Estados Partes reconocen que todo niño tiene el derecho intrínseco a la vida. 2. Los Estados Partes garantizarán en la máxima medida posible la supervivencia y el desarrollo del niño». De igual forma, la Convención Interamericana de Derechos Humanos (1984), establece que «toda persona tiene derecho a que se respete su vida. Este derecho estará protegido por la ley y, en general, a partir del momento de la concepción. Nadie puede ser privado de la vida arbitrariamente» (art. 4.1).

Las medidas de protección en favor de los niños tienen como fundamento la vulnerabilidad de ellos, pues los derechos de los niños convencionalmente asegurados constituyen derechos complementarios respecto de los que poseen todas las personas (cfr. Nogueira, 2017, p. 424).

Por otro lado, el Código Civil ecuatoriano señala:

«El nacimiento de una persona fija el principio de su existencia legal, desde que es separada completamente de su madre. La criatura que muere en el vientre materno, o que, perece antes de estar completamente separada de su madre, se reputará no haber existido jamás. Se presume que la criatura nace con vida; quien alegue lo contrario para fundamentar un derecho, deberá probarlo» (art. 60).

Además de la protección a la vida se debe garantizar su calidad, que está dada desde el derecho a tener una familia, misma que es considerada como el núcleo fundamental de la sociedad, lo que desencadena una variedad de beneficios a la persona, como la identidad, salud, nutrición, educación, cultura, entre otros.

\section{II.2 La sociedad ecuatoriana y el abandono de niños recién nacidos}

El ambiente familiar, considerado como fundamental para un efectivo desarrollo de los niños, puede ser negado por diversas causas, y de entre ellas 
se destaca el abandono. La Convención sobre los Derechos del Niño recoge los siguientes beneficios:

«Art. 20.1. Los niños temporal o permanentemente privados de su medio familiar, o cuyo superior interés exija que no permanezcan en ese medio, tendrán derecho a la protección y asistencia especiales del Estado.

2. Los Estados Partes garantizarán, de conformidad con sus leyes nacionales, otros tipos de cuidados para esos niños.

3. Entre esos cuidados figurarán, entre otras cosas, la colocación en hogares de guarda, la kafala del derecho islámico, la adopción, o de ser necesario la colocación e instituciones adecuadas de protección de menores. Al considerar las soluciones, se prestará particular atención a la conveniencia de que haya continuidad en la educación del niño y a su origen étnico, religioso, cultural y lingüístico».

En el mundo islámico existe lo que se llama "kafala", una institución legal que permite hacerse responsable del cuidado, protección y educación de un menor de edad, sin necesidad de realizar un procedimiento de adopción, ni ejercer la figura de la patria potestad.

«Esta figura no crea un vínculo de filiación entre el menor de edad (denominado makful) y la persona responsable de su cuidado (llamado kafil); es decir, el menor de edad no adquiere el apellido de la persona que será responsable de su cuidado y en relación al derecho sucesorio, el menor de edad no se convierte el legítimo heredero por la inexistencia de filiación» (Ortega, 2015, pp. 819-826).

La kafala islámica se puede equiparar a la figura del acogimiento familiar que existe en el Ecuador, pero está muy lejos de la figura del acogimiento institucional que conlleva la adopción del menor de edad, instituciones (acogimiento familiar y acogimiento institucional) que se explicará más adelante y con mayor amplitud.

El Estado ecuatoriano, al haber ratificado un acuerdo internacional que garantiza la protección de los menores que carecen de un hogar, ratifica su compromiso en el Código de la Niñez y Adolescencia, estableciendo que la adopción tiene como finalidad insertar al niño en un hogar idóneo, de carácter permanente y definitivo, siempre que en niño se encuentre legalmente en la posición de ser adoptado.

El Observatorio de los Derechos de la Niñez y Adolescencia (2010, pp. 25 y ss.) ha realizado una primera encuesta nacional de la niñez y adolescencia de la sociedad ecuatoriana muy interesante. El análisis muestra que una de las instituciones sociales tradicionales, la familia, deja profundas huellas en el desarrollo de la infancia, por ser agente de socialización primaria y fuente de transmisión de valores. En este sentido, Volpi y Fachini (2015, p. 115) concuerdan en que la moral familiar coloca la honra femenina en una posición muy valorada y, por tanto, el abandono puede configurar un 
universo de crisis familiar o, también, el estado de miseria en que se encuentra la familia que abandona. Por ello, según los autores, abandonar una criatura, podría ser una oportunidad de un destino mejor para ésta. Respecto a ello, la solución de los buzones estatales para dejar a niños en condiciones seguras, podría significar un mejor destino para el neonato, dado que el Estado asumirá la responsabilidad de su vida y salud.

Un artículo publicado por IBEC Corporation (2013, s/p) apunta a que el tema de la pobreza y la imposibilidad de lograr un acceso adecuado a satisfacción de necesidades básicas, desata el hecho de que madres abandones a sus hijos por razones como: embarazos no deseados, falta de apoyo familiar, frustraciones mentales, falta de educación adecuada y principios morales.

Según los datos publicados por el Instituto Latinoamericano de la Familia (2016, pp. 8 y ss.) el total de nacimientos vivos registrados en el año 2014 es de 284.203 , de los cuales 54.727 son registros tardíos de niños entre 1 a 3 años. Como se ve, el número de registros tardíos es significativo. Por otro lado, el mismo documento da cuenta de que en ese año 79.350 niños nacieron dentro de matrimonio y 150.126 fuera de éste (principalmente de madres solteras y con uniones no legalizadas). Otro dato importante es el que se toma entre noviembre de 2013 a octubre de 2014 y que indica que el cuidado de menores de 5 años está confiado en un $76.6 \%$ a la madre. Todas estas cifras pueden arrojar luces sobre posibles causas de abandonos de niños recién nacidos, aunque, ciertamente, no son determinantes. El hecho de que una mujer afronte un embarazo no deseado en condiciones inoportunas social o económicamente puede generar el abandono del niño recién nacido. Por ello, es relevante el papel que el Estado juega en la protección del niño abandonado, en pro de sus derechos de vida y protección.

En consonancia con la información oficial antedicha, se han encontrado datos adicionales en otras fuentes que traen consigo datos dignos de reflexión y análisis. La página electrónica del Ministerio del Interior de Ecuador destaca que, entre 2012 a 2014, se registraron 25 casos de niños abandonados en calles y hospitales, cuyo principal problema de salud, a la hora de su rescate, es la hipotermia. Cuando son encontrados se trasladan a centros de salud a fin de estabilizarlos y luego se entregan en centros de acogida que son regentados por el Ministerio de Inclusión Económica y Social o fundaciones, se explica en esta página.

La prensa nacional ha dado cuenta sobre abandono de niños recién nacidos: «Una bebé de dos horas de nacida es encontrada en la basura» (Beltrán, 4-XII-2016); «Un bebé de dos días de nacido fue encontrado envuelto en una funda en el sur de Quito con signos de hipotermia» (Alarcón, 8-I-2017); «en medio de matorrales y basura se escuchó el llanto de un bebé» 
(...) recién nacida en el interior de una funda de basura en una calle desolada (...)» (Merizalde, 10-VII-2017); «un bebé de apenas siete horas de nacido fue abandonado en medio de la carretera la noche del 13 de julio de 2017» (Merizalde, 14-VII-2017); «a través del proyecto Bebés al Cielo, 51 fetos y cadáveres de recién nacidos que fueron hallados en basureros, baños y barrios capitalinos recibieron sepultura la mañana de hoy miércoles 26 de julio...» (Merizalde, 26-VII-2017). «Un bebé de entre 24 y 48 horas de nacido fue abandonado» (Castillo, 4-III-2018); «una misa para dar digna sepultura a 40 bebés fallecidos encontrados en basureros, servicios higiénicos o en la calle y que no han sido reconocidos o reclamados por sus familias se realizará (...)» (Bravo, 11-III-2018). «Una bebé de aproximadamente 48 horas de nacida fue abandonada» (Bravo, 1-II-2018). «Los restos del recién nacido fueron localizados por un vecino del sector» (Moreta, 29-XII-2017).

Así mismo, un diario ecuatoriano (El Telégrafo, 21-II-2017), a propósito del hallazgo de un niño recién nacido en un basurero de una parroquia urbana en Salcedo, provincia del Cotopaxi, informa que la Dirección Nacional de Policía Especializada de Niños y Niñas de Ecuador, cuantificó que en 2016 hubo 17 casos de niños recién nacidos abandonados (11 hombres y 6 mujeres) y 13 en 2015 (5 mujeres y 8 hombres)

Estos datos numéricos proporcionan un escenario que evidencia que muchos niños y niñas recién nacidos son abandonados a su suerte en Ecuador. Estos niños bien podrían ser depositados en buzones estatales y en condiciones seguras. Es la propuesta que esta investigación aborda a través de la supremacía de los derechos del niño y de la obligación estatal de no descuidarlos.

\section{OBLIGACIONES LEGALES E INSTITUCIONALES DEL ESTADO CON RESPECTO AL NIÑO}

El Estado, frente al interés superior del niño y en especial de aquellos que carecen de hogar o que han sido privados de una familia biológica, ha creado dos figuras para prevenir el abandono y de acceso inmediato en beneficio de niños, como son: el acogimiento familiar y el acogimiento institucional. Ambos son medios de protección a los menores que funcionan hasta que puedan ser reinsertados a su hogar biológico o accedan al proceso de adopción. Los arts. 220 y 232 del Código de la Niñez y Adolescencia recogen dos ideas esenciales sobre la materia:

(i) El acogimiento familiar siempre tiene la característica de temporalidad, la que debe ser dispuesta por autoridad judicial competente. 
Mientras el niño se encuentre bajo esta custodia, se buscará reinsertarlo a su familia biológica mediante el fortalecimiento de los vínculos familiares.

(ii) El acogimiento institucional, como última medida preventiva, se caracteriza por ser una medida transitoria de protección, igualmente dispuesta por autoridad judicial — cuando no pueda aplicarse el acogimiento familiar-; para lo cual, las instituciones de acogida deben encontrarse debidamente autorizadas por lo organismos que designe el Estado para su regulación y control. La institución de acogida del menor de edad debe procurar que el niño sea reintegrado a su hogar biológico y si el proceso resultare negativo para el menor, deberá procurar su adopción.

Sobre la regulación de los hogares de acogida institucional, consta la Ley Orgánica de Hogares de Protección Social de Ecuador (1937), la cual les otorga a dichas instituciones un nombre genérico "Hogares de Protección Social", subordinadas actualmente al Ministerio de Inclusión Económica y Social. Para los niños en estado de orfandad (abandonados) se han creado los Orfelinatos, cuyo objeto es «sustituir al hogar y proporcionar a los niños huérfanos de ambos sexos de 3 a 6 años de edad, los halagos de una vida familiar tranquila» (art. 11).

La primera observación que presenta la Ley Orgánica de Protección Social es que solo regula el cuidado de niños o niñas huérfanos de 3 a 6 años de edad, dejando un vacío en cuanto al momento del nacimiento hasta los 3 años de edad. Este vacío se corrige con la aparición del Reglamento General para las instituciones de Protección de Menores de Ecuador de 1988, que establece la naturaleza de servicio de los orfelinatos u hogares para huérfanos:

«Son establecimientos destinados a dar protección y cuidado permanente a los menores que a partir de su nacimiento, hasta los seis años de edad, por presentar un estado manifiesto de orfandad o de abandono familiar, por lo que, para asegurar el normal crecimiento y desarrollo en términos de salud, afecto, educación, etc., requieren de la atención del Estado en este tipo de institución» (art. 1).

Además, se rescata que el Ecuador ha tomado medidas preventivas frente a la posible inexistencia de hogares en busca de adopción e idóneos para adoptar, por lo que ha ratificado acuerdos internacionales como la Convención para la protección de los niños en materia de adopción.

El Informe del Consejo Nacional para la Igualdad Intergeneracional (2014, pp. 131-132) señala que las respuestas del Estado para cubrir las necesidades de protección especial de las personas en la primera etapa de vida requieren un inminente y necesario fortalecimiento. Indica que dentro de la estructura institucional del Ministerio de Inclusión Económica y Social del Ecuador existe otra instancia con un rol fundamental en la protección 
especial de niños y niñas: la Subsecretaria de Protección Especial, encargada de ofrecer servicios de protección a los niños y niñas, entre otros, desprovistos de un medio familiar. Para el caso de atención a niños y niñas desprovistos de ambiente familiar por violación de sus derechos o por abandono, la Subsecretaría se encarga del manejo y rectoría de todo el proceso de acogimiento: institucional de administración directa, familiar y a través de convenios con organizaciones de la sociedad civil. Según los datos de la Subsecretaría, en 2013 los niños y adolescentes que tuvieron que ser atendidos fueron 44.850; de ellos, 876 se cubrieron por instituciones de acogimiento familiar, 2.600 por acogimiento institucional y 31.254 por el programa de erradicación de trabajo infantil.

Otro acuerdo internacional es el Convenio de funcionamiento con Aldeas Infantiles SOS Internacional (2013), una ONG que tiene por objeto «proveer en instituciones y programas pedagógicos, asistencia profesional y cuidado a niños, adolescentes y jóvenes adultos huérfanos, abandonados o separados de sus familias (...) en conformidad con idea de Aldeas Infantiles SOS de Hermann Gmeiner (...)» (art. 2). Este acuerdo guarda estrecha relación con el Convenio Básico de Cooperación con SOS (1994, arts. 2 y 3 ), que tiene por objeto buscar la integración a la sociedad como un proceso de inclusión, a los niños y niñas huérfanos y abandonados, sin discriminación alguna, de conformidad al desarrollo económico social de nuestro país, y con proyectos vinculados al sector público y privado.

\section{ACOGIMIENTO INSTITUCIONAL ESTATAL}

\section{IV.1. Deberes del Estado}

El Estado, como garante de los derechos fundamentales de las personas, tiene obligación de prever políticas públicas que permitan que esos derechos se efectivicen en la cotidianidad de la vida de los pueblos. En líneas anteriores hemos visto que las cifras nacionales relacionadas con los niños recién nacidos, con su situación económica y social, y su situación de abandono o desprotección, tienen una entidad suficiente para que el Estado ecuatoriano aborde la problemática e intente dar soluciones sostenibles. También queda anotado que existe un marco normativo en Ecuador que garantiza el acogimiento de niños en situación de abandono. La operatividad de esta norma está sobre todo en manos del Ministerio de Inclusión Económica y Social.

Si, como ya se ha analizado, el abandono de niños recién nacidos se verifica en condiciones que probablemente causen su deceso, entonces una iniciativa estatal para acoger a estos expósitos es indispensable, a efectos de 
precautelar el derecho supremo de la vida. Un acercamiento a experiencias mundiales de acogimiento institucional estatal de niños recién nacidos abandonados da luces sobre la cuestión.

\section{IV.2. Buzones para entregar bebés en condiciones seguras o "Babyklappe"}

Anna Bermeo (2016, s/p) nos dice que «el concepto de abandonar un niño es chocante, y desafía nuestras nociones básicas como padres y plantea interrogantes importantes sobre el derecho de los niños a la vida, la familia y la identidad». En su artículo, la autora explica cómo algunos padres abandonan de forma anónima a sus bebés recién nacidos en buzones para bebés o Baby Box, que se ubican en hospitales e iglesias en Alemania.

Bermeo anota que existe un precedente histórico, pues la práctica de abandonar niños era muy común en los años medievales:

«Los primeros buzones - llamados ruedas de expósitos, o en italiano, routas dei trovatelli- fueron instalados en 1198 en las iglesias. El Papa Inocencio III puso en marcha este sistema en hogares para niños huérfanos, con el objetivo de reducir el asesinato del recién nacido en Italia».

La autora termina indicando que actualmente existen alrededor de 200 buzones para recibir niños recién nacidos en condiciones seguras en Alemania, Polonia, República Checa, Italia, Rusia, Eslovaquia, Suiza y Bélgica; así como también algunos países como China, Japón, Malasia y Corea del Sur. Además aporta algunos otros datos que a continuación comentaremos (cfr. Bermeo, 2016).

Babyklappe es un término utilizado en Alemania y alude a la creación de buzones para evitar la muerte de recién nacidos por congelamiento y reducir la tasa de abortos y filicidios. Tales buzones son colocados en hospitales, centros sociales o iglesias y que son puertas en una pared exterior que se abren para que el bebé sea depositado en condiciones seguras; además, contiene una carta para la madre ofreciendo asesoramiento y un número de teléfono al que contactar para ayuda o información adicional. Una alarma anuncia la llegada del bebé que es atendido durante ocho semanas y si la madre no lo reclama, es dado en adopción.

Por otro lado, en países como Alemania también existe la posibilidad de "nacimiento anónimo", que es una práctica mediante la cual las madres pueden dar a luz a su bebé sin que su identidad sea revelada. El dilema del derecho fundamental a la identidad se resuelve cuando la persona cumple 16 años, pues si es su deseo se les revela la identidad de su madre biológica. El parto anónimo es legal en Luxemburgo y Austria; en Francia se niega a los 
progenitores cualquier derecho a establecer relación con su hijo; en Italia no es necesario que se introduzca el nombre de la madre en el acta de nacimiento del niño; y, en República Checa y Grecia, la identidad de la madre se registra.

Un dato interesante de un estudio realizado por el Instituto Alemán de la Juventud revela que los servicios anónimos habían perdido el rastro de la quinta parte de todos los bebés abandonados en buzones para bebés. Por eso, no extraña que las Naciones Unidas hayan solicitado a Suiza en el año 2015 prohibir los buzones para bebés, por contravenir el art. 7 de la Convención sobre Derechos del Niño y que tiene que ver con el derecho a conocer y ser cuidado por los padres. Igual recomendación se formuló a Alemania.

El principal argumento a favor de estos buzones es el derecho fundamental a la vida. Nosotros estamos de acuerdo con esta premisa, por cuanto el buzón genera una alternativa segura para quien ha tomado la decisión de abandonar al recién nacido y lo hace en condiciones precarias. $\mathrm{Y}$ aunque Bermeo resalta que un estudio alemán arroja que el número de niños abandonados ilegalmente no disminuyeron por la introducción de estos buzones, el hecho de que uno solo de estos niños quede en condiciones seguras si es abandonado, justificaría la iniciativa.

Cristian Palacios (2015) hace un análisis de si al parto anónimo sirve como mecanismo jurídico-administrativo para evitar el aborto, reducir el abandono de niños recién nacidos y crear una política pública que frene el tráfico de neonatos. El autor define al parto anónimo como una prerrogativa de la madre de reservarse el derecho de reconocer al hijo que ha dado a luz; una cuestión de política pública familiar: su aceptación, tolerancia o reproche dependerán de los esquemas y pautas que se tengan sobre la libertad individual y sexual, sobre la posibilidad de ejercer una maternidad responsable y sobre otros valores que permean el ordenamiento jurídico. Para Palacios, dos son los alcances de esta figura: que se sobrepone a la idea de que la madre es siempre conocida, ya que ésta se ampara en el anonimato de su identidad, y, que descanse sobre el campo de la ponderación de principios y valores. Se debe decidir, según el autor, entre el derecho a vivir o a conocer la causa biológica por la que se vive.

Ciertamente es una cuestión que conlleva reflexión y debate jurídicosocial. Un derecho y otro, en aparente pugna. El profesor argentino Eduardo Llugard (2018) ha dicho que «los derechos constitucionales se argumentan y se ponderan, porque están basados en principios». De tal manera que, para este profesor, «los derechos constitucionales se complementan unos a otros; y, se desplazan, cuando hay argumento y motivación suficiente para ello». En consecuencia, el derecho de identidad se desplazaría por el derecho a la vida. 
Palacios (2015) afirma que el parto anónimo pretende garantizar la vida de aquel cuyo potencial nacimiento puede estar en peligro por autonomía de la voluntad de la madre, y que, aun materializándose su nacimiento, su situación de peligro muta en condiciones de existencia. Finalmente concluye que el parto anónimo es un mecanismo jurídico alternativo, que se ubica por detrás de la penalización absoluta del aborto y por delante de la legalización del mismo, como recurso plausible entre los peores males posibles que atentan contra la vida del nasciturus y contra la estabilidad de la madre, como instrumento de rescate que piensa en la madre y el hijo.

Otro interesante estudio es el de Monika Dittrich y Cristina Papaleo (2013) sobre el parto anónimo frente a los buzones, en el que se considera la propuesta alemana de una ley que permitiría dar a luz de forma anónima en un hospital. Ahí se recogen testimonios como el de la directora del Servicio Social Católico de Colonia, Monika Kleine, quien ha señalado que muy a menudo los recién nacidos ven la luz en un sótano, en un baño o en un galpón, entornos peligrosos y sin asistencia médica. En Colonia, en la Casa Adelheid existe un buzón para entregar niños recién nacidos en condiciones seguras; allí, en doce años fueron abandonados 19 niños. Las autoras alegan que no conocer el propio origen puede generar graves problemas psíquicos y que el Tribunal Constitucional alemán dictaminó en 1989 que todos los seres humanos tienen derecho a conocer su procedencia y que el Consejo Ético de Alemania ha criticado la práctica del abandono anónimo de niños, exigiendo al Gobierno buscar una solución para mujeres embarazadas en situación de emergencia. Dittrich y Papaleo muestran que 130 hospitales alemanes tienen este tipo de ofertas provisorias y aceptadas, pero no están aún reguladas por la ley.

Para la funcionaria del Instituto de Minoridad de Múnich, Monika Bradna, las normas unificadas para todas las variantes de entrega anónima de niños y calidad en el asesoramiento de las madres, es urgente. No es suficiente, ha dicho, el argumento de que buzones y partos anónimos salvan vidas. Cree que estas iniciativas deben ser analizadas y deben producir estadísticas oficiales, porque eventualmente podrían fomentar el abandono de recién nacidos, por las facilidades que representa para las madres.

El año 2011 en Austria, luego de diez años de existencia de buzones para entregar bebés en condiciones seguras y aprobación del parto anónimo, se ha evitado el abandono descontrolado e incluso el homicidio de recién nacidos (cfr. nota de prensa, EFE, 2011). Esto se debió a que en 2001 una modificación legal en ese país despenalizó el abandono de niños en estos "nidos" y permitió a las mujeres dar a luz sin informar su identidad y entregar sus hijos. Ese año quince hospitales austríacos han puesto en 
marcha estos buzones y actualmente la mayoría de grandes clínicas de esa nación ofrecen asesoría y atención médica para el parto anónimo.

Sin duda, los buzones para entrega de neonatos en condiciones seguras y el parto anónimo generan gran debate social. Aun así, consideramos que son opciones válidas que podrán permitir salvaguardar la vida humana, que constituye una obligación constitucional primordial del Estado.

\section{VIABILIDAD JURÍDICA Y ESTATAL PARA ESTABLECER BUZONES PARA ENTREGAR BEBÉS EN ECUADOR EN CONDICIONES SEGURAS}

El ordenamiento jurídico ecuatoriano pone énfasis en el compromiso estatal frente a la protección de los menores de edad, con especial atención a quienes se encuentran en estado de orfandad, fundamentalmente para la protección de la vida. Esto se encuentra plasmado en la Constitución, en los tratados internaciones, y en otras normas como acuerdos con ONG, Código Orgánico de la Niñez y Adolescencia, Código Orgánico Integral Penal y normativa de regulación de Hogares de Protección de Menores de Edad, en donde se busca la absoluta protección de la vida de toda persona, desde su concepción.

Para que el proyecto de buzones para entregar niños recién nacidos en condiciones seguras sea factible en el Ecuador y se ajuste a la normativa interna, los legisladores se deben enfocar en la reforma del art. 153 del Código Orgánico Integral Penal, que sanciona a todas las personas que incurren en el abandono de menores. La reforma debería conservar el artículo en su totalidad, y agregar un inciso que exima de sanciones a las personas que entreguen voluntariamente a recién nacidos en los lugares debidamente autorizados por el Estado, con el objeto de buscar un hogar idóneo para éstos. Esta reforma busca proteger la vida de un recién nacido, permitiendo que sea puesto en manos de especialistas que puedan verificar el estado de salud del menor y ubicarlo en un orfelinato después de haber sido autorizado por un juez; así mismo, procura evitar el abandono clandestino y riesgoso de niños y niñas. Ello tendría un gran impacto social por el cambio de reglas en relación a las obligaciones de los padres con sus hijos; de todas maneras, comparado con el interés superior del niño y su derecho a la vida, no representaría esto un mayor obstáculo.

Tal reforma además debería incluir el Código Civil y el Código de la Niñez y Adolescencia, por tener mayor relación al tema planteado. En adición, debería dictarse un reglamento de funcionamiento del proyecto de buzones para dejar niños recién nacidos en condiciones seguras. 
Finalmente, hemos de tomar en cuenta la Opinión Consultiva OC17/2002 de 28 de agosto de 2002 de la Corte Interamericana de Derechos Humanos, que establece la obligatoriedad del Estado con respecto a adoptar medidas para la protección y el cuidado de niños abandonados «por tratarse de un sector social muy vulnerable, incluso sujeto a mayor protección que la población en situación de peligrosidad (...)». A la par conviene recordar que nuestra Constitución determina que los niños, niñas y adolescentes tienen derecho a tener una familia y disfrutar de la convivencia familiar y comunitaria, lo cual no se afecta porque previo a realizar un abandono bajo el proyecto buzones estatales para dejar niños en condiciones seguras, se tiene la opción del acogimiento familiar y en caso de no poder realizarlo, se procederá con el abandono en condiciones seguras, buscando la protección del menor.

\section{CONCLUSIONES}

1. Los documentos que se han citado en esta investigación dan cuenta de un importante número de niños recién nacidos abandonados a su suerte en situaciones precarias, lo que eleva el índice de mortalidad de neonatos.

2. Elementos que pueden ocasionar el abandono de estos niños son: la estigmatización social que sufren las adolescentes embarazadas, las circunstancias sociales y económicas de los padres del niño abandonado y el maltrato físico y sicológico que sufren las mujeres embarazadas.

3. El Estado está llamado a garantizar la vida del recién nacido, al igual que la del resto de ciudadanos, sin discriminación alguna. Ecuador tiene incorporados los derechos constitucionales en su sistema jurídico interno, así como también ha ratificado acuerdos internacionales a fin de cumplir con esta obligación estatal. Para el efecto ha creado las figuras de acogimiento familiar, donde se busca la reinserción del menor de edad a su familia biológica; y, como segunda opción, el acogimiento institucional para declarar al menor de edad en estado de adopción.

4. Aunque las estadísticas de abandono de recién nacidos pueden no ser alarmantes, la vida de una sola persona es importante frente a nuestra legislación, y al encontrarse el Estado obligado a defender sus derechos, debe crear medidas de protección.

5. El objetivo de esta investigación es delinear una propuesta para crear una política estatal que permita el abandono de niños recién nacidos en circunstancias seguras, en sitios previamente establecidos por el Estado para el efecto (buzones para dejar niños recién nacidos en condiciones seguras), y que prevea las condiciones de recuperación del menor, en caso de 
arrepentimiento, en un determinado plazo. La misma política debe prever la posibilidad de adopción en caso de que el niño no sea reclamado dentro del plazo establecido.

6. Con base en lo anterior, se sugiere sustituir el art. 153 del Código Orgánico Integral Penal por el siguiente:

«Abandono de persona.- La persona que abandone a personas adultas mayores, niñas, niños $\mathrm{y}$ adolescentes, mujeres embarazadas, personas con discapacidad o quienes adolezcan de enfermedades catastróficas, de alta complejidad, raras o huérfanas, colocándolas en situación de desamparo y ponga en peligro real su vida o integridad física, será sancionada con pena privativa de libertad de uno a tres años».

Las lesiones producto del abandono de persona, se sancionarán con las mismas penas previstas para el delito de lesiones, aumentadas en un tercio.

Si se produce la muerte, la pena privativa de libertad será de dieciséis a diecinueve años.

Se exceptúan a la presente disposición a aquellas personas que entreguen voluntariamente a recién nacidos en lugares debidamente autorizados por el Estado, con el objeto de que se busque un hogar idóneo para éstos». 


\section{REFERENCIAS}

Alarcón, I. (8-I-2017). Un bebé fue encontrado envuelto en una funda en el sur de Quito. El Comercio. En http://www.elcomercio.com/actualidad/bebe-encontrado-fundasur-quito.html (último acceso 10-VII-2019).

Anónimo (2013). Abandono infantil en el Ecuador. IBEC Corporation: Ibec For You. En http://www.ibecmagazine.com/GESTIÓNSOCIAL/TabId/460/ArtMID/1166/A rticleID/913/ABANDONO-INFANTIL-EN-EL-ECUADOR-.aspx (último acceso 24-VII-2019).

Barahona, A. (2015). Igualdad, familia y matrimonio en la Constitución ecuatoriana de 2008. Revista Foro, (23), 72, pp. 69-94.

Beltrán, B. (4-XII-2016). Una bebé recién nacida fue abandonada y rescatada por la Policía. El Comercio. En http://www.elcomercio.com/actualidad/bebe-reciennacidaabandonada-sanantonio.html (último acceso 10-VII-2019).

Bermeo, A. (2016). Niños abandonados en buzones de bebés. Medio Ambiente y Periodismo. En http://medioambienteyperiodismo.blogspot.com/2016/01/ninosabandonados-en-buzones-de-bebes.html_(último acceso 10-VII-2019).

Bravo, D. (1-II-2018). Bebé fue abandonada al interior de una maleta en Puembo. El Comercio. En http://www.elcomercio.com/actualidad/bebe-abandonada-maletapuembo-dinapen.html_(último acceso 10-VII-2019).

Bravo, D. (11-III-2018). Una misa para dar sepultura a 40 niños abandonados en basureros, servicios higiénicos o en la calle. El Comercio. En http://www.elcomercio.com/ actualidad/bebes-abandonados-quito-misa-sepultura.html (último acceso 10VII-2019).

Cabanellas, G. (1993). Diccionario Jurídico Elemental. Nueva edición actualizada. En https://es.slideshare.net/YuhryGndara/diccionariojuridicoelementalguillermocabanellas (último acceso 10-VII-2019).

Castillo, L. (4-III-2018). Un bebé recién nacido fue abandonado en Cuenca. El Comercio. En http://www.elcomercio.com/actualidad/bebe-recien-nacido-abandonadocuenca.html (último acceso 10-VII-2019).

Consejo Nacional para la Igualdad Intergeneracional (2014). Plan Internacional, Observatorio Social del Ecuador. La niñez y adolescencia en el Ecuador Contemporáneo: avances y brechas en el ejercicio de derechos. Unicef. En https://www.unicef.org/ecuador/NA_Ecuador_Contemporaneo.pdf (último acceso 12-VII-2019).

Corte Interamericana de Derechos Humanos (2002). Opinión consultiva OC-17/2002: sobre la Condición Jurídica y Derechos Humanos del Niño. En http://www.corteidh.or.cr/docs/opiniones/seriea_17_esp.pdf_(último acceso 12VII-2019).

Dittich, M. Papaleo, C. (2013). Parto anónimo: ¿mejor que el buzón para bebés? Deutsche Welle (DW) Made for Minds. En https://www.dw.com/es/parto-anónimo-mejorque-el-buzón-para-bebés/a-16666078_(último acceso 18-VII-2019). 
Donna, E. (1999). Derecho Penal, Parte Especial, t. I. Talcahuano: Rubinzal-Culzoni.

EFE (2011). Los 'buzones' para abandonar niños en condiciones seguras en Austria cumplen 10 años. 20 Minutos. Madrid. En: https://www.20minutos.es/noticia/1189328/0/buzones-babyklappe/abandononinos/austria/ (último acceso 10-VII-2019)

Fernández Álvarez, M. (2002). Casadas, Monjas, Rameras y Brujas. Barcelona: Espasa.

Instituto Latinoamericano de la Familia. (2016). M. Matute Piedra \& G. Jarrín Pinos (eds.). Familia en cifras - Ecuador 2016, 2a ed. Loja: Ediloja.

Lacruz Berdejo, J. (2011). Derecho de familia. El matrimonio y su economía. Pamplona: Aranzandi.

Larrea Holguín, Juan. (2008). Manual Elemental de Derecho Civil del Ecuador. Nociones preliminares sobre el Derecho, la ley y Personas. vv. 1 y 2. Quito: CEP.

Lludgar, E. (2018). Teoría de los Derechos Constitucionales. Curso Latinoamericano de Alta Formación en Derecho Constitucional y Procesal Constitucional. En https://www.youtube.com/watch?v=74DIMUY3508 (último acceso 5-VIII-2019).

Merizalde, M. (10-VII-2017). Una recién nacida fue hallada en una funda en San Mateo de Chillogallo, sur de Quito. El Comercio. En el sitio web http://www.elcomercio.com/actualidad/bebe-hallazgo-funda-chillogalloquito.html_(último acceso 10-VII-2019).

Merizalde, M. (14-VII-2017). Un recién nacido fue abandonado en una carretera en el cantón Pedro Vicente Maldonado, en Pichincha. El Comercio. En http://www.elcomercio.com/actualidad/bebe-abandonado-carreterapedrovicentemaldonado-pichincha.html (último acceso 10-VII-2019).

Merizalde, M. (26-VII-2017). 51 fetos y cadáveres de recién nacidos abandonados fueron sepultados. El Comercio. En http://www.elcomercio.com/tendencias/bebescadaveres-reciennacidos-sepultura-bebesalcielo.html (último acceso 10-VII-2019).

Ministerio del Interior del Ecuador (s/f). En 33 meses, Dinapen recuperó a 25 niños y niñas abandonados en calles $y$ hospitales. En el sitio web oficial https://www.ministeriodegobierno.gob.ec/en-33-meses-dinapen-recupero-a-25ninos-y-ninas-abandonados-en-calles-y-hospitales/ (último acceso 17-XI-2019).

Moreta, M. (29-XII-2017). Restos de un recién nacido fueron devorados por perros en la parroquia Santa Rosa, en Ambato. El Comercio. En http://www.elcomercio.com/actualidad/restos-bebe-devorado-perrosambato.html_(último acceso 10-VII-2019).

Noguerira, H. (2017). La protección convencional de los Derechos de los Niños y los estándares de la Corte IDH sobre medidas especiales de protección por parte de los Estados Partes respecto de los niños, como fundamento para asegurar constitucionalmente los Derechos de los Niños y Adolescentes. Revista Ius Et Praxis, 2, pp. 415-462.

Observatorio de los Derechos de la Niñez y Adolescencia (2010). Los niños y niñas del Ecuador a inicios del siglo XXI. Una aproximación a partir de la primera encuesta nacional de la niñez y adolescencia de la sociedad civil. Unicef. En 
https://www.unicef.org/ecuador/Encuesta_nacional_NNA_siglo_XXI_2_Parte1 .pdf (último acceso 24-VII-2019).

Ordás, M. (2015). El parto anónimo a debate. Revista Nuevos Paradigmas de las Ciencias Sociales Latinoamericanas, 11, pp. 97-144.

Ortega, A. (2015). La Kafala de Derecho Islámico: Concepto, Naturaleza Jurídica, Caracteres y Efectos Jurídicos en España. Revista Actualidad Jurídica Iberoamericana, (3), 819-826.

Ossorio, M. (1974). Diccionario de Ciencias Jurídicas Políticas y Sociales. En https://conf.unog.ch/tradfraweb/Traduction/Traduction_docs\%20generaux/Dicc ionario $\% 20 \mathrm{de} \% 20 \mathrm{Ciencias} \% 20 \mathrm{Juridicas} \% 20$ Politicas $\% 20 \mathrm{y} \% 20$ Sociales $\% 20$ \%20Manuel\%20Ossorio.pdf_(último acceso 24-VII-2019).

Palacios, C. (2015). Parto anónimo y aborto. Revista Jurídica Digital Enfoque Jurídico. En https://enfoquejuridico.org/2015/06/16/parto-anonimo-y-aborto/ (último acceso 24-VII-2019).

Petit, E. (2014). Tratado Elemental de Derecho Romano. México: Porrúa.

Redacción Sociedad. (21-II-2017). El abandono de los menores de edad se incrementó durante el último año en el país. El Telégrafo. En https://www.eltelegrafo.com.ec/noticias/sociedad/4/el-abandono-de-losmenores-de-edad-se-incremento-durante-el-ultimo-ano-en-el-pais (último acceso 10-VII-2019).

Robles, F. (2017). Derecho Penal Parte Especial I: Manual Autoformativo Interactivo. En https://repositorio.continental.edu.pe/bitstream/continental/4249/1/DO_UC_31 2_MAI_UC0191_2018.pdf_(último acceso 19-VII-2019).

Sanín, A. (2013). Abandono infantil: estado de la cuestión. Textos y Sentidos, 7, pp. 1-30. En http://biblioteca.ucp.edu.co/ojs/index.php/textosysentidos/article/view/810 (último acceso 16-VII-2019).

Unicef Comité Español (1989). Convención sobre los Derechos del Niño. En https://www.unicef.es/sites/unicef.es/files/convencion_derechos_nino_integra.p df (último acceso 24-VII-2019).

Villada, J. (2004). Delitos contra las personas. Homicidio, Aborto, Lesiones, Duelo, Abuso de Armas, Abandono, Omisión de Auxilios. Buenos Aires: La Ley.

Volpi, S.A. Fachini Da Silva, J. (2015). Hijos de nadie: la práctica del abandono domiciliario en el mundo lusobrasileño en perspectiva comparada. Revista Latinoamericana de Población, 17, pp. 101-118. 